\title{
EDITORIAL
}

\section{Was non-utilisation of computed tomography as a public health tool a costly lapse in closing the pandemic?}

\section{Anirudh Kohli}

Chief Radiologist Breach Candy Hospital Trust, 60 Bhulabhai Desai Road, Mumbai, Maharashtra, India. E-mail: dranirudhkohli@gmail.com

The present pandemic is progressing unabatedly even with extensive education of the masses, severe lockdowns and all measures to contain human to human transmission of SARS COV-2. Previous coronavirus episodes were well contained especially in 2002-2003 (SARS COV 1). Then what is different now. Evidently, there are missing keys in closing this pandemic.

SARS COV 1 infected 8100 individuals that too in a limited geographical area and was brought under control in 8 months. ${ }^{[1]}$ Essentially by detecting the symptomatic and isolating them, utilizing temperature testing and clinical evaluation for lower respiratory tract symptoms.

When SARS COV 2 (2020) arrived, similar measures were used as those to control SARS COV 1.

However, there is one major difference between SARS COV 1 (2002/2003) and SARS COV 2 (2020- ?). The virus mainly replicated in the lower respiratory tract in SARS COV 1; thus, patients were symptomatic. SARS COV 2 replicates in both upper and lower respiratory tract ${ }^{[2]}$ as a result up to $80 \%$ of transmission of SARS COV 2 has been by asymptomatic carriers. ${ }^{[3]}$ Asymptomatic carriers have viral loads as high as symptomatic as well as even the symptomatic start shedding virus days before they become symptomatic. This has been borne out by numerous studies. An editorial in New England Journal Asymptomatic transmission the Achilles heel of current control strategies of COVID 19 in April 2020 bring these points out very lucidly. ${ }^{[1]}$

The gold standard for detection of SARS COV 2 is RTPCR. This has a high false-negative rate. Only a 70\% positivity, that too in a short bandwidth of $5^{\text {th }}$ to $8^{\text {th }}$ day from exposure. ${ }^{[4]}$ Individuals with false-negative RTPCR which is a large percentage will not be isolated and continue to spread the virus in the community. Some of these false-negative RTPCR may be detected on a second or third RTPCR. But, on what basis would a second or third RTPCR be asked, especially if they are asymptomatic. Additionally, the turnaround time of RTPCR can be up to $24-48 \mathrm{~h}$ thus allowing the individual to continue shedding the virus in society.

Thus, the crux of the continued spread of the pandemic has been the asymptomatic carriers and false negativity of the RTPCR.

Numerous articles especially from China in the early part of the pandemic demonstrated a high sensitivity for computed tomography (CT) chest in CT scan in COVID 19 in both RTPCR positive and negative individual. ${ }^{[5,6]}$ Also early into the pandemic (Feb 2020) the largest cohort of cases outside china was on the diamond princess cruise ship. And $54 \%$ of the asymptomatic RTPCR positive individuals on this cruise ship had a positive CT for imaging appearances of COVID 19 pneumonia. ${ }^{[7]}$ A number of studies and meta-analysis have supported positive CT studies in asymptomatic individual. ${ }^{[8-10]}$ This prompted a thought process on the use of CT scan to assist in the detection of COVID 19. [11] However, guidelines/recommendations issued by national societies early in the pandemic (March 2020) dissuaded from using CT as a screening tool for COVID 19 even though publications from China advocated the utility of CT as a public disease control tool. ${ }^{[12]}$

The main reasons cited in the guidelines were as follows:

- Low specificity of CT, as its imaging appearances may overlap those of other viral pneumonia and other chronic lung diseases. However, in a pandemic where the primary aim is to contain the spread of the virus, sensitivity is the key and not specificity. ${ }^{[13]}$

- Advocacy of CT may overwhelm existing resources as well as may reduce access of non-COVID patients to imaging suites. In fact, as the pandemic has raged imaging volumes for non-COVID patients have drastically dropped, possibly a combination of the disappearance of diseases, or patients are scared to visit health-care facilities for fear of contracting SARS COV 2. ${ }^{[14,15]}$

- Additionally, it was considered CT may act as a potential transmitter of SARS COV 2 via surface 
contamination, especially exposure to imaging department staff. Numerous articles in the early part of the pandemic educated the radiology community on care in the imaging department to prevent the spread of SARS COV 2 within the department. ${ }^{[16]}$ In a pandemic imaging services need to be of value in the frontline and not shy away from their discharge of an important utility.

Finally, there was concern on the utilization of ionizing radiation. There are numerous means to reduce the radiation and achieve low dose CT studies, minimizing the utilization of ionizing radiation. ${ }^{[13]}$ In a pandemic where there is significant loss of life and livelihood, the possibility of unproven deleterious effects occurring a few decades later should not take away from the primary focus of controlling the pandemic and its devastation. The pros and cons need to be balanced with rational thinking.

A number of these guidelines also used symptomatology as a criterion for advocating CT scan. Recommending only in individuals with moderate to severe symptoms, when the RTPCR was negative or not available. ${ }^{[17]}$ These guidelines missed the basic point off the possibility of CT being positive in asymptomatic and false negative RTPCR individual. What is also surprising is these guidelines were published in the early part of the pandemic when countries like USA had only witnessed 1000 cases. By now tens of millions have been infected; however, till date there has been no revision in the guidelines.

One of the missing keys, probably the most important, has been the utilization of $\mathrm{CT}$ as a public health tool to reduce the false negative rate of RTPCR as well as detect asymptomatic individuals carrying and spreading SARS COV 2. The Chinese authorities advocated the use of CT and helped contained the spread to 86,000 with 4,600 deaths. ${ }^{[18]}$

What could the world have done differently or maybe needs to rethink and do differently. CT scanners should have been deployed actively into field areas like COVID screening centres. Only a quick plain CT study of the chest requires minimal time and minimal skill. This be linked up electronically to central reporting areas where radiologists could remotely screen these individuals providing a rapid advisory whether the individual should isolate and undergo a repeat RTPCR if negative. This would have detected so many asymptomatic spreaders which is the key to the spread of COVID 19.

Though imaging has played a role in the management of COVID 19 pneumonia, it seems to have missed its untapped utility as a public health tool to contain the spread of SARS COV 2.
$\mathrm{CT}$ could have been centre stage contributing immensely by helping detect asymptomatic false-negative carriers of SARS COV 2 thus minimizing the suffering and economic hardships the present pandemic has inflicted on our planet.

\section{References}

1. Gandhi M, Yokoe DS, Havlir DV. Asymptomatic Transmission, the Achilles' Heel of Current Strategies to Control Covid-19. N Engl J Med 2020;382:2158-60.

2. Cheng PKC, Wong DA, Tong LKL, Ip S-M, Lo ACT, Lau C-S, et al. Viral shedding patterns of coronavirus in patients with probable severe acute respiratory syndrome. Lancet 2004;363:1699-700.

3. Nikolai LA, Meyer CG, Kremsner PG, Velavan TP. Asymptomatic SARS Coronavirus 2 infection: Invisible yet invincible. Int J Infect Dis 2020;100:112-6.

4. Woloshin S, Patel N, Kesselheim AS. False negative tests for SARS-CoV-2 infection-Challenges and implications. N Engl J Med 2020;383:e38.

5. Ai T, Yang Z, Hou H, Zhan C, Chen C, Lv W, et al. Correlation of chest CT and RT-PCR testing in Coronavirus disease 2019 (COVID-19) in China: A report of 1014 cases. Radiology 2020;296:E32-40.

6. Fang Y, Zhang H, Xie J, Lin M, Ying L, Pang P, et al. Sensitivity of chest CT for COVID-19: Comparison to RT-PCR. Radiology 2020;296:E115-7.

7. Inui S, Fujikawa A, Jitsu M, Kunishima N, Watanabe S, Suzuki Y, et al. Chest CT findings in cases from the cruise ship "Diamond Princess" with Coronavirus disease 2019 (COVID-19). Radiol Cardiothorac Imaging 2020;2:e200110.

8. Kronbichler A, Kresse D, Yoon S, Lee KH, Effenberger M, Shin JI. Asymptomatic patients as a source of COVID-19 infections: A systematic review and meta-analysis. Int J Infect Dis 2020;98:180-6.

9. Parry AH, Wani AH, Yaseen M, Shah NN, Dar KA. Clinicoradiological course in coronavirus disease-19 (COVID-19) patients who are asymptomatic at admission. BJR Open 2020;2:20200033.

10. Tsikala Vafea M, Atalla E, Kalligeros M, Mylona EK, Shehadeh F, Mylonakis E. Chest CT findings in asymptomatic cases with COVID-19: A systematic review and meta-analysis. Clin Radiol 2020;75:876.e33-9.

11. Kohli A. Can imaging impact the coronavirus pandemic? Indian J Radiol Imaging 2020;30:1-3.

12. ACR Recommendations for the use of Chest Radiography and Computed Tomography (CT) for Suspected COVID-19 Infection American college of radiology ACR.ORG : March 112020.

13. Kalra MK, Homayounieh F, Arru C, Holmberg O, Vassileva J. Chest CT practice and protocols for COVID-19 from radiation dose management perspective. Eur Radiol 2020:1-7. doi: 10.1007/ s00330-020-07034-x [Epub ahead of print]

14. Boeken T, Le Berre A, Mebazaa A, Boulay-Coletta I, Hodel J, Zins M. Non-COVID-19 emergencies: Where have all the patients gone? Eur Radiol 2020;30:5220-1.

15. Naidich JJ, Boltyenkov A, Wang JJ, Chusid J, Hughes D, Sanelli PC. Impact of the Coronavirus disease 2019 (COVID-19) pandemic on imaging case volumes. J Am Coll Radiol 2020;17:865-72.

16. Kohli A. COVID 19- Tips for getting back to work. Indian J Radiol Imaging 2020;30:105-10.

17. Rubin GD, Ryerson CJ, Haramati LB, Sverzellati N, Kanne JP, Raoof $\mathrm{S}$, et al. The role of chest imaging in patient management during the COVID-19 pandemic: A multinational consensus statement from the Fleischner society. Radiology 2020;296:172-80. 
18. Fan L, Liu S. CT and COVID-19: Chinese experience and recommendations concerning detection, staging and follow-up. Eur Radiol 2020;30:5214-6.

\begin{tabular}{|l|l|}
\hline \multicolumn{2}{|c|}{ Access this article online } \\
\hline Quick Response Code: & \\
\hline & Website: \\
\hline & www.ijri.org \\
\cline { 2 - 3 } & DOI: \\
\hline
\end{tabular}

Cite this article as: Kohli $\mathrm{A}$. Was non-utilisation of computed tomography as a public health tool a costly lapse in closing the pandemic? Indian J Radiol Imaging 2021;31:S1-3.

Received: 31-Dec-2020

Revised: 31-Dec-2020

Accepted: 31-Dec-2020
This is an open access journal, and articles are distributed under the terms of the Creative Commons Attribution-NonCommercial-ShareAlike 4.0 License, the identical terms. 